\title{
STRUCTURE AND PROPERTIES OF WELD METAL MODIFIED BY NANOOXIDES
}

\author{
V.D. KUZNETSOV and D.V. STEPANOV \\ NTTU «Kiev Polytechnic Institute» \\ 37 Pobeda Ave., 03056, Kiev, Ukraine. E-mail: v.kuznetsov@kpi.ua
}

\begin{abstract}
Given are the results of investigation of structure and properties of weld metals at introduction of nanooxide powders into weld pool. It is shown that portion of nanooxides, being introduced in the weld pool, should not exceed $0.5 \%$ in a range of recommended modes of welding of low-alloy steels. It is determined that nanooxides introduction results in formation of mainly non-metallic inclusions in nanosize range of $0.07-$ $0.13 \mu \mathrm{m}$ as well as in $0.3-0.8 \mu \mathrm{m}$ range. At that increased content of carbon, titanium, oxygen, aluminum and manganese are observed in them in comparison to reference welds. It is shown that introduction of $0.5 \%$ titanium nanooxide reduces content of brittle constituents of the structure and content of acicular ferrite rises to $40 \%$, that results in 2 times increase of impact toughness together with simultaneous increase of yield strength. It is shown that modifying of weld metal by titanium and aluminum nanooxides reduces solidification interval, that can indicate their effect as 2nd type inoculants. 15 Ref., 3 Tables, 6 Figures.
\end{abstract}

Keywords: weld, low-alloy steel, nanopowder, nanooxides, structure, non-metallic inclusions, mechanical properties, solidification interval

Analysis of investigations and publications of recent years indicates a role of non-metallic inclusions (NMI) as factor for regulation of structure and properties of cast metal. It is shown $[1,2]$ that inclusions engineering can be used for steel microstructure optimizing. Inclusions (oxides, sulfides, carbides) of $<1 \mu \mathrm{m}$ size, promoting nucleation of acicular ferrite (AF), are referred to a separate group due to their small size, and they are called dispersoids having no negative effect on reduction of mechanical properties, but determining the conditions of metal microstructure formation.

Works [3-6] studied effect of NMI size on heterogeneous nucleation of AF structure as well as content and peculiarities of distribution of NMI in presence of aluminum oxides, titanium oxides and nitrides.

Systematic researches in this direction were made by staff members of the E.O. Paton Electric Welding Institute. Works [7-13] experimentally studied and theoretically grounded effect of carbides, nitrides and oxides on level of AF formation and increase of mechanical properties of weld metal of low-alloy steels.

Peculiarity of works indicated above is study of role of NMI, including of nanosize range, being formed in weld metal at corresponding changes of concentration of introduced elements and their reactions with oxides, nitrides, carbides formation, as well as when not more than $1 \mu \mathrm{m}$ size

elements are introduced via charge of flux-cored wire and in form of nanosize powder inoculants.

Development of works in this direction requires accumulation and analysis of experimental data applicable to range of low-alloy steels as well as schemes of introduction of nanosize particles in the weld pool.

Aim of this work is investigation of effect of NMI on structure and properties of weld metals at direct introduction of nanooxide powders in the weld pool.

Investigations for detection of general dependencies were carried out in welding of low-alloy steels 09G2S and 10G2FB with Sv10KhGN2SMFTYu wire as well as steel A-514 (18GSKhNF) with Sv-09G2S wire. In all the cases welding was performed in $\mathrm{Ar}+28 \% \mathrm{CO}_{2}$ gas mixture at $12.3 \mathrm{~kJ} / \mathrm{cm}$ heat input.

Nanocomponents were introduced in the weld pool in form of addition alloy after pressing and baking of homogeneous mixture of iron powder of $40 \mu \mathrm{m}$ fraction and nanosize powders of aluminum or titanium oxides $(27-41 \mathrm{~nm})$ with set volume relationship.

Prepared addition alloy was used as consumable electrode of set length and diameter, embeded in a groove along the butt length before welding [14]. In this case effect of processes, related with passing of nanopowders via arc, was eliminated.

Examination of structure and NMI were carried out by methods of optical and electron microscopy using Neophot-30 microscope, electron scanning microscope JSM 35CF with attachment for local X-ray analysis INCA Energy 350 as well 
as computer programs developed at the E.O. Paton Electric Welding Institute for analysis of microstructure constituents and distribution of NMI by size and composition. Thermal-physical characteristics of cast metal were investigated using NETZSCH thermal analyzers DSK 404F1.

Investigations showed that amount of nanopowder introduced in the weld pool results in change of amount of NMI in the weld metal.

Dependence of general volume fraction of NMI on content of aluminum nanooxides in the weld are given in Figure 1.

If NMI fraction in the reference weld makes $0.45 \%$ then introduction in the weld pool of nanopowder of aluminum oxide in $0.5 \%$ amount promotes for rapid increase of fraction of NMI to $0.65 \%$. Introduction of aluminum oxide nanopowder in $0.5-2.5 \mathrm{vol}$ \% range does not have significant effect on volume fraction of NMI. Further growth to more than $2.5 \%$ of nanopowder results in rise of NMI volume fraction from 0.70 to $0.86 \%$.

However, results of evaluation of structural changes for indicated range of introduced nanopowders showed that exceed of volume fraction above $0.5 \%$ is not accompanied by significant structural changes.

Figure 2 for example shows structure of weld metal in welding of $09 \mathrm{G} 2 \mathrm{~S}$ steel for indicated range of changes of volume fraction of aluminum oxide nanopowder.

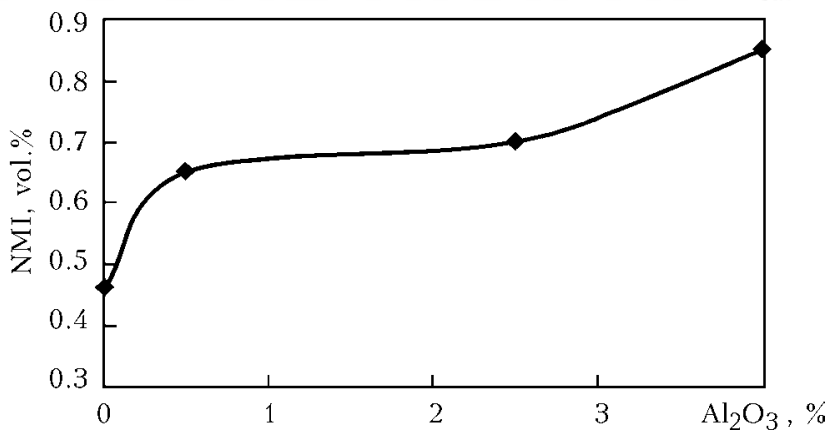

Figure 1. Dependence of NMI volume fraction on content of aluminum nanooxides in weld metal in welding of steel 09G2S using Sv-0KhGN2SMFTYu wire

Formation of structure, the main constituents of which are precipitation of polygonal ferrite, acicular and lamellar ones with ordered and disordered secondary phases, takes place in the weld metal under initial conditions. The peculiarity of this structure is presence of coarse constituents of indicated morphological forms of ferrite ( $\mathrm{Fi}^{-}$ gure 2,a). Microhardness of constituents changes from $H V 145$ to $H V 187$.

Microstructure of weld metal with addition of $\mathrm{Al}_{2} \mathrm{O}_{3}$ nanopowder in $0.5 \%$ amount has refined dispersed structure mainly consisting of upper bainite, partially lower and acicular ferrite (Figure $2, b$ ). Microhardness of constituents changes from $H V 264$ to $H V 304$.

Weld metal with addition of $\mathrm{Al}_{2} \mathrm{O}_{3}$ nanopowder in amount of $2.5 \%$ volume fraction has microstructure of intra-granular ferrite and ferrite with ordered and disordered secondary phases

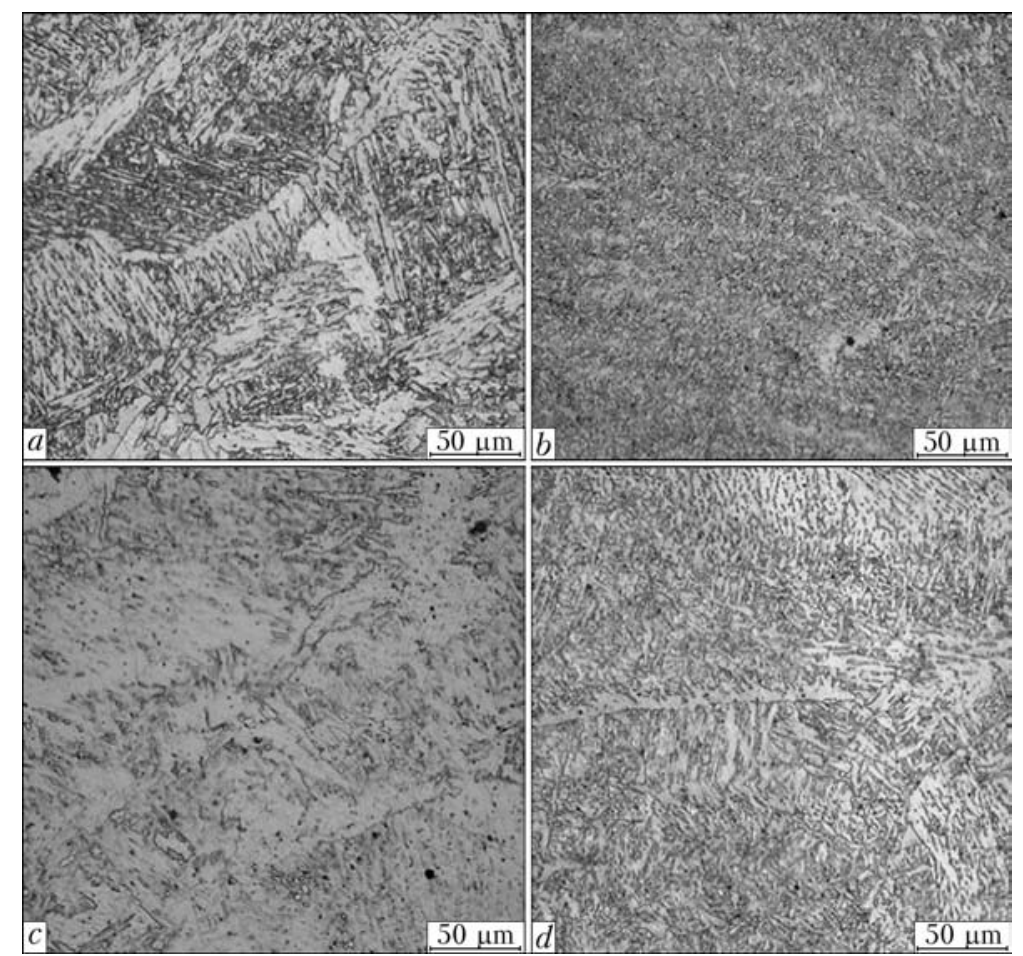

Figure 2. Microstructure of reference weld $(a)$ and weld with addition of nanopowder $\mathrm{Al}_{2} \mathrm{O}_{3}$ in amount of $0.5(b), 2.5$ (c) and $4.5(d) \%$ 

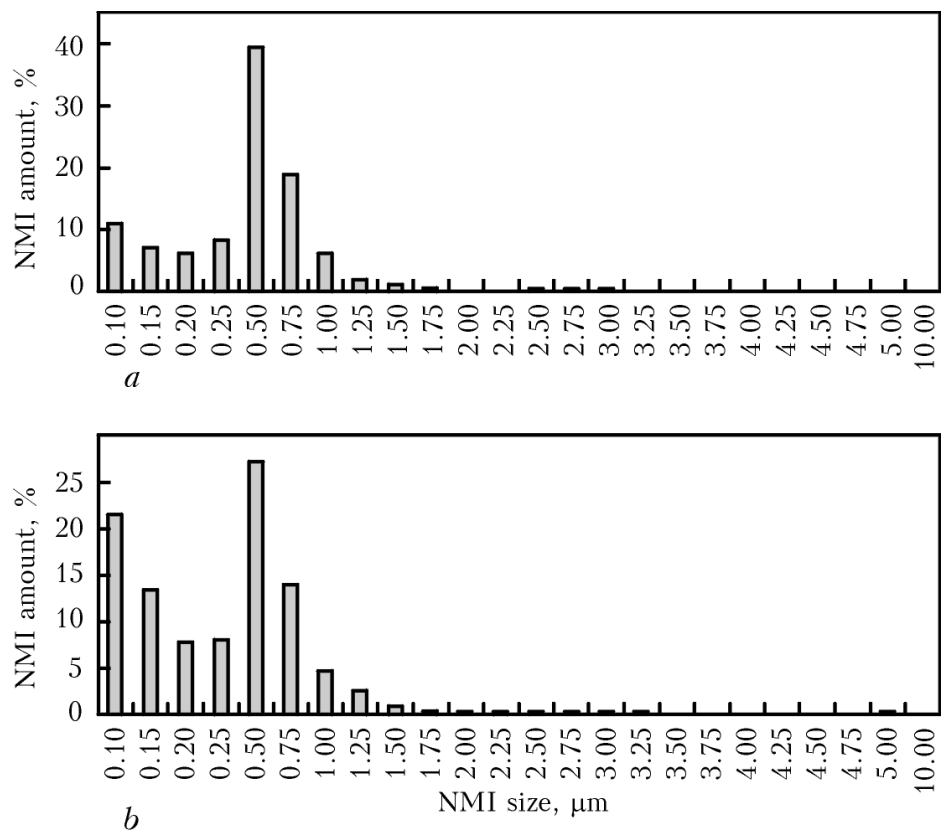

Figure 3. Histogram of NMI distribution by size: $a$ - in reference weld; $b-$ in weld with addition of aluminum oxide in $0.5 \%$ amount

(Figure 2,c). Microhardness of constituents virtually does not change and stays in $H V$ 180-189 limits.

Addition of $\mathrm{Al}_{2} \mathrm{O}_{3}$ nanopowder in amount of $4.5 \%$ results in formation in the structure of intra-granular ferrite with precipitates of $\mathrm{AF}$ and ferrite with ordered secondary phases (Figure 2, d). Microhardness of constituents changes from $H V 188$ to $H V 236$.

It can be concluded that the main role in formation of structure with increased strength and toughness properties plays nanooxides being introduced only in small amount (0.5\%), and increase of their concentration, apparently, promotes for coagulation and coalescence with NMI of material during solidification of the weld pool and has no significant effect on structure formation.

In fact, computer processing of results of distribution of NMI by size allowed selecting three size ranges from total data array, i.e. inclusions of to $0.3 \mu \mathrm{m}$, from 0.3 to $0.8 \mu \mathrm{m}$ and more than $0.8 \mu \mathrm{m}$.

The peculiarity of NMI in the weld metal is their smaller size range at nanooxides introduction into the weld pool (Figure 3 ).

Thus, if from 5 to 10 inclusions of the reference weld fall for $0.10-0.25 \mu \mathrm{m}$ and from 5 to 40 inclusions for $0.5-1 \mu \mathrm{m}$ size range, then in the case of nanooxide introduction the first range covers from 8 to 22 inclusions and the second from 5 to 27 inclusions.

Found dependencies are also verified by the results of processing of size of only spherical inclusions by index of diameter of equivalent circumference. For example, Figure 4 gives the hy- grograms on volume content and distribution of such inclusions in the weld metal for initial state and with inclusion of nanooxides.

The main part of spherical inclusions from 4 to $6 \%$ falls for the range of up to $0.3 \mu \mathrm{m}$ size as well as for the ranges of $0.3-0.8 \mu \mathrm{m}$ and more in the initial state without addition of nanopowder oxide. At that, up to $9 \%$ precipitation of particles of $0.31-0.37 \mu \mathrm{m}$ size are observed ( $\mathrm{Fi}^{-}$ gure $4, a$ ).

Addition of $\mathrm{TiO}_{2}$ nanopowder in 0.5 vol.\% amount promotes for rise from 6 to $14 \%$ of part of spherical inclusions of $0.3 \mu \mathrm{m}$ as well as 0.30 $0.55 \mu \mathrm{m}$ size. At that, no inclusion of more than $0.8 \mu \mathrm{m}$ size can be virtually observed ( $\mathrm{Fi}^{-}$ gure $4, b$ ).

Results of local spectral analysis of chemical composition of the inclusions showed that significant increase of carbon, oxygen, aluminum, sulfur, titanium, manganese concentration is observed in each of them independent on size. This is particularly obvious for carbon, oxygen and sulfur (several orders).

Introduction of nanooxides, in keeping the general pattern on content of indicated elements, somewhat changes it to the side of larger content of oxygen, aluminum and titanium, that indicates presence of oxides of these elements in the inclusions.

Analysis of triple diagrams of oxides of $\mathrm{SiO}_{2}-$ $\mathrm{Al}_{2} \mathrm{O}_{3}-\mathrm{MnO}$ and $\mathrm{TiO}_{2}-\mathrm{Al}_{2} \mathrm{O}_{3}-\mathrm{MnO}$ systems for the most typical range of inclusion size $0.3-$ $0.8 \mu \mathrm{m}$ also verifies increased content of $\mathrm{Al}_{2} \mathrm{O}_{3}$ and $\mathrm{TiO}_{2}$ oxides (Figure 5). 

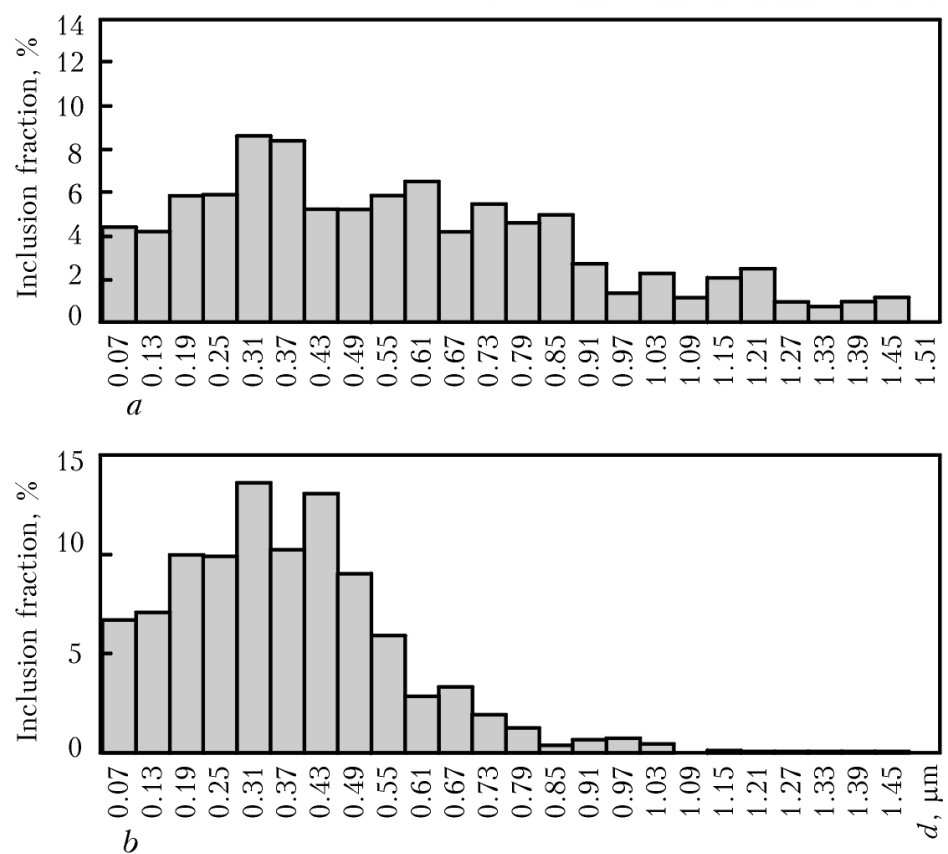

Figure 4. Histogram of distribution of inclusions in weld metal by diameter of equivalent circumference $d: a-$ in initial condition; $b$ - weld with 0.5 vol. $\% \mathrm{TiO}_{2}$ nanooxide in welding of $10 \mathrm{G} 2 \mathrm{FB}$ steel
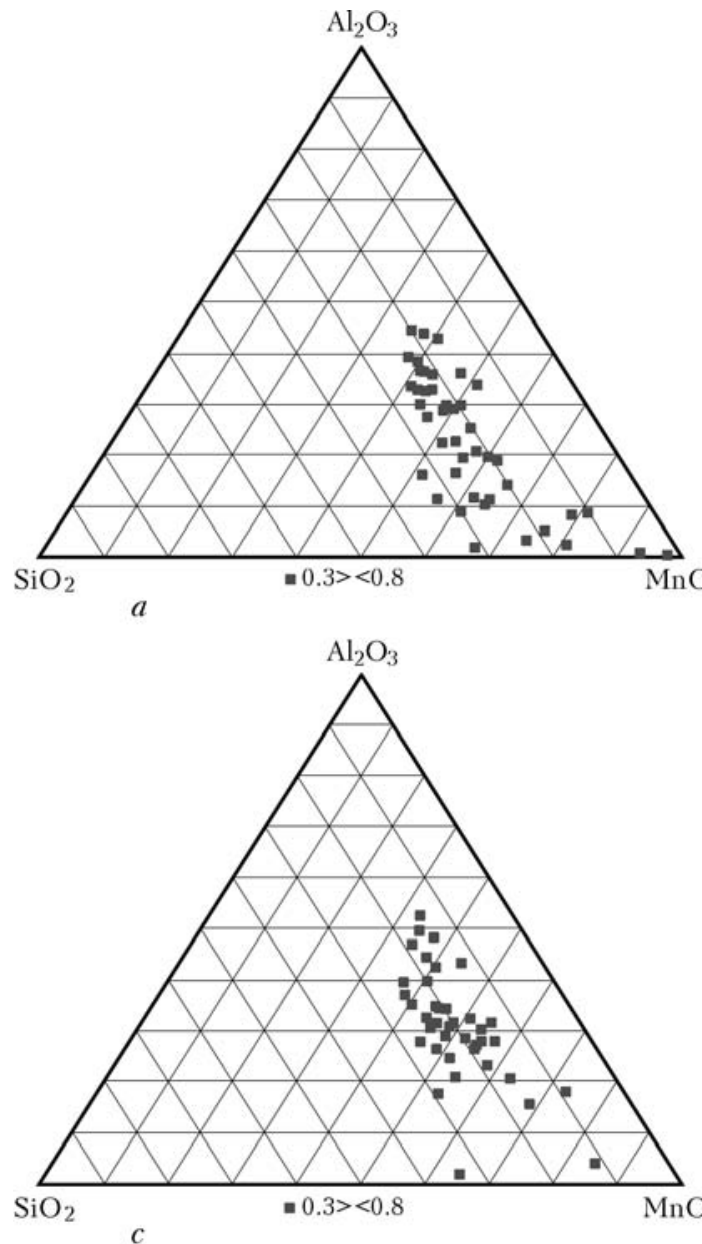
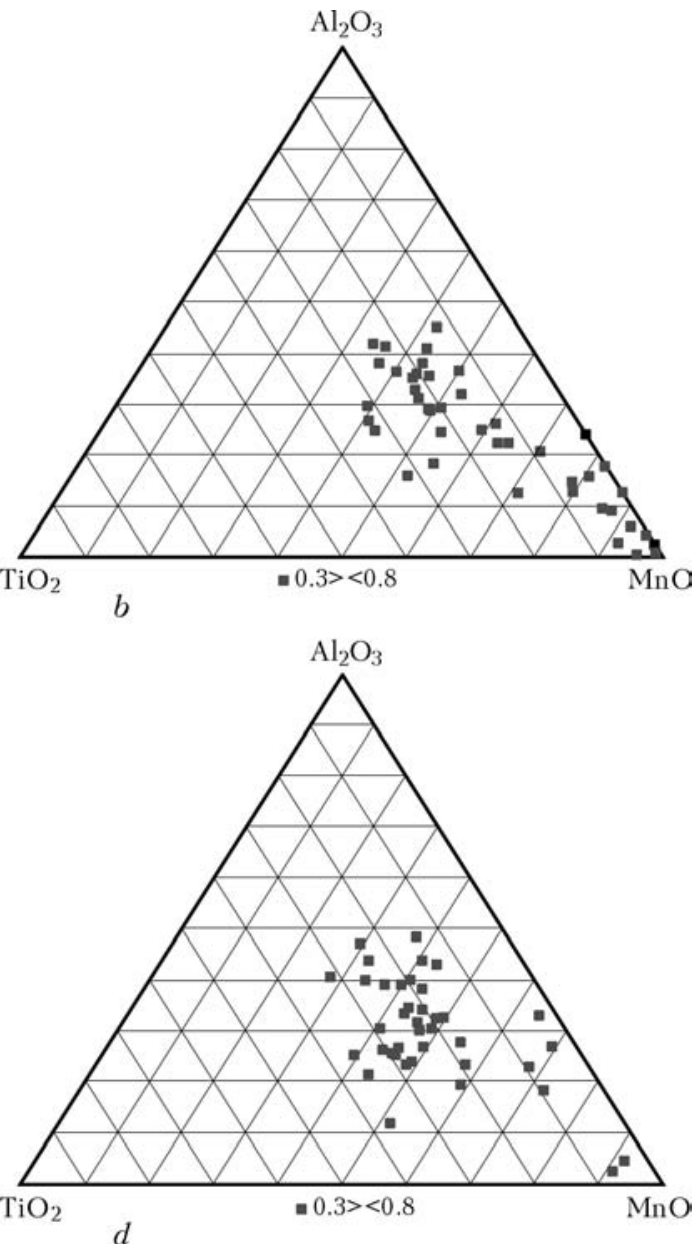

Figure 5. Triple diagrams of oxides of $\mathrm{SiO}_{2}-\mathrm{Al}_{2} \mathrm{O}_{3}-\mathrm{MnO}$ and $\mathrm{TiO}_{2}-\mathrm{Al}_{2} \mathrm{O}_{3}-\mathrm{MnO}$ system: $a, b-$ reference weld; $c, d-$ weld with $0.5 \% \mathrm{TiO}_{2}$ 
WELDING PRODUCTION CHAIR of NTUU «KPI» is 80

Table 1. Typical morphological forms of ferrite in weld metal structures

\begin{tabular}{||l|c|c|c|c|c|c||}
\hline \multirow{2}{*}{\multicolumn{1}{|c|}{ Studied weld }} & \multicolumn{6}{c|}{ Constituents of microstructure of weld metal, $\%$} \\
\cline { 2 - 8 } & BF & LF & AF & UB & LB & WF \\
\hline Reference weld without nanooxides & Up to 10 & $10-20$ & Up to 10 & $20-40$ & $20-40$ & Up to 35 \\
\hline Weld with $0.5 \% \mathrm{TiO}_{2}$ nanooxide & Up to 10 & Up to 10 & $20-40$ & $10-20$ & $10-15$ & Up to 15 \\
\hline
\end{tabular}

Thus, if significant part of inclusions of one as well as another systems in the reference weld contains from 50 to $90 \% \mathrm{MnO}$, up to $40 \%$ of $\mathrm{Al}_{2} \mathrm{O}_{3}$ and to $20 \% \mathrm{TiO}_{2}$ (Figure 5, $a, b$ ), then introduction in the weld pool of $0.5 \% \mathrm{TiO}_{2}$ provides for high $\mathrm{MnO}$ concentration only in separate inclusions, and presence of $\mathrm{Al}_{2} \mathrm{O}_{3}$ as well as $\mathrm{TiO}_{2}$ in the inclusions exceeds to 55 and $40 \%$, respectively (Figure $5, c, d$ ).

Thus, complex analysis of inclusions indicates significant difference in their sizes, distribution density and content in metallic matrix at nanooxide introduction, which has effect on weld metal structure.

In fact, results of metallographic analysis determined that the most wide-spread morphological forms of ferrite in the weld metal structure are block ferrite (BF), lamellar ferrite (LF), intra-granular AF, Widmanstatten ferrite (WF), upper (UB) and lower bainite (LB). Percent content of each of forms in the investigated welds in welding of $10 \mathrm{G} 2 \mathrm{FB}$ steel is given in Table 1.
Initial structure of welds is characterized by increased content of brittle constituents (BF, WF, UB) and formation of AF to $10 \%$ with high coefficient of shape $(L / B$ of $4-7)$ and aciculars of up to $20 \mu \mathrm{m}$ length.

Microstructure of weld metal has sufficiently high content of intra-granular polygonal ferrite with precipitation along the boundaries of grains of xenomorphic ferrite (Figure 6, $a-c$ ). Welds with such structure are characterized by low level of toughness and ductility of metal. Values of microhardness of structural constituents vary from $H V 231$ to $H V 253$.

Weld metal structure with $\mathrm{TiO}_{2}$ in $0.5 \%$ amount is characterized by reduced content of brittle constituents (BF, WF, UB) and increased AF content to $40 \%$ with more favorable coefficient of shape ( $L / B$ of $3-5$ ) and aciculars' length to $5 \mu \mathrm{m}$ in comparison with reference structure (Figure 6, $d-f$ ).

Welds with such structure are characterized by combination of sufficiently high level of indices of toughness, ductility and strength. The
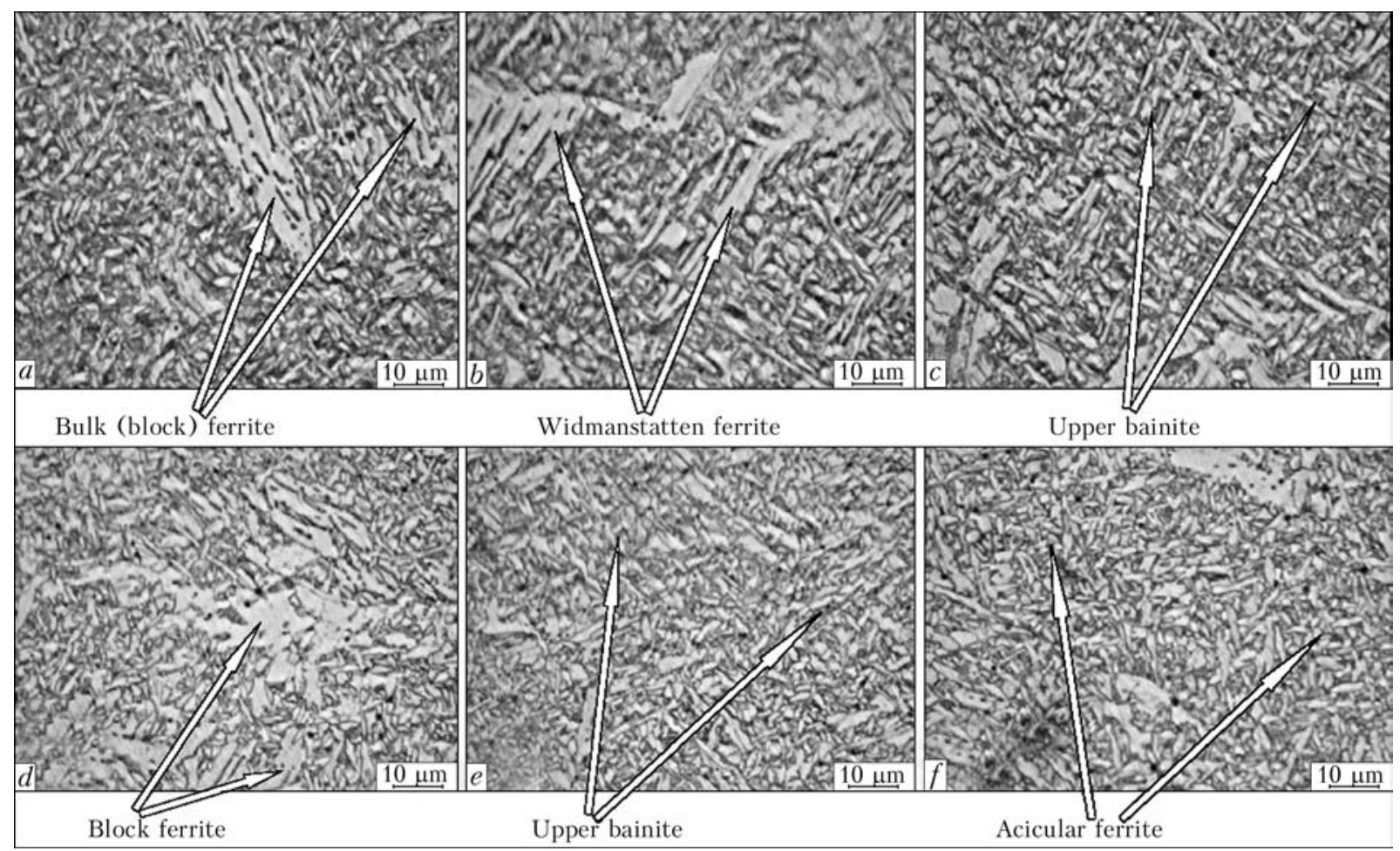

Figure 6. Typical structure of weld metal without nanooxides $(a-c)$ and with 0.5 vol.\% $\mathrm{TiO}_{2}(d-f)$ 
Table 2. Results of mechanical tests of weld metal in welding of A-514 (18GSKhNF) steel using 09G2S wire

\begin{tabular}{|c|c|c|c|c|c|}
\hline Studied metal & $\begin{array}{c}\text { Yield strength } \sigma_{y} \\
\mathrm{MPa}\end{array}$ & $\begin{array}{c}\text { Tensile strength } \\
\sigma_{\mathrm{t}}, \mathrm{MPa}\end{array}$ & $\begin{array}{c}\text { Relative } \\
\text { elongation, \% }\end{array}$ & $\underset{\%}{\text { Reduction in area, }}$ & $\begin{array}{c}\text { Impact toughness } \\
K V C, \mathrm{~kJ} / \mathrm{m}^{2}\end{array}$ \\
\hline Without nanopowders & 357 & 542 & 21 & 61 & 4.6 \\
\hline With $\mathrm{TiO}_{2}$ nanooxide in $0.5 \%$ amount & 514 & 647 & 18 & 54 & 9.3 \\
\hline
\end{tabular}

measurements show that microhardness of structural constituents varied from $H V 230$ to $H V 250$.

Thus, introduction of nanooxides, in particular titanium, in the weld pool results in positive structural changes from the point of view of formation of tough morphological forms of ferrite, that promotes for increase of weld metal mechanical properties (Table 2).

As follows from data of Table 2, increase of yield strength for $157 \mathrm{MPa}$ and strength for $105 \mathrm{MPa}$ is observed at introduction of titanium nanooxides in the weld pool. At that, impact toughness also increases 2 times. Thus, the common point, independent on grade of investigated low-alloy steel and type of introduced nanooxides, is change of size, distribution density, composition of the inclusions as well as their positive effect on structure and mechanical properties of weld metal.

Role of introduced nanooxides in structureforming is also shown by data of thermograms of differential scanning calorimetry. The investigations found the differences in melting temperatures as well as in solidification of metal modified by nanooxides (Table 3 ).

The general dependence is some reduction of weld metal melting temperature at nanooxides introduction. It is the well-known fact that nanostructural materials differ by significantly lower melting temperature [15], therefore, some reduction of liquidus temperature can be related with presence of nanooxides in the weld metal. Reduction of melting temperature is developed in different ways for titanium and aluminum oxides. Thus, if melting temperature of the reference metal is $1543.4{ }^{\circ} \mathrm{C}$, then its reduction to $1535.8{ }^{\circ} \mathrm{C}$ is observed at introduction of $0.5 \%$ $\mathrm{TiO}_{2}$ and to a greater extent, i.e. $1522.5^{\circ} \mathrm{C}$, at $1 \% \mathrm{Al}_{2} \mathrm{O}_{3}$.

At the same time, increase of solidification temperature of weld metal, modified by nanooxides, except for $1 \% \mathrm{Al}_{2} \mathrm{O}_{3}$, is observed. At that, the general dependence is in reduction of interval of solidification of modified metal, independent on investigated range of changes of volume fraction of introduced nanooxides.

Thus, it makes $43.9{ }^{\circ} \mathrm{C}$ for the reference metal, then observed reduction for the investigated range of changes of each of nanooxides is virtually
Table 3. Thermal-physical characteristics of weld metal

\begin{tabular}{||l|c|c|c||}
\hline \multicolumn{1}{|c|}{ Metal content } & $T_{\mathrm{L}},{ }^{\circ} \mathrm{C}$ & $T_{\mathrm{S}},{ }^{\circ} \mathrm{C}$ & $\Delta T,{ }^{\circ} \mathrm{C}$ \\
\hline Reference & 1543.4 & 1499.5 & 43.9 \\
\hline $0.5 \% \mathrm{TiO}_{2}$ & 1535.8 & 1524 & 11.8 \\
\hline $1 \% \mathrm{TiO}_{2}$ & 1540.6 & 1527.7 & 12.9 \\
\hline $0.5 \% \mathrm{Al}_{2} \mathrm{O}_{3}$ & 1541.9 & 1518.6 & 23.3 \\
\hline $1 \% \mathrm{Al}_{2} \mathrm{O}_{3}$ & 1522.5 & 1499 & 23.5 \\
\hline $\begin{array}{l}\text { Note. } T_{\mathrm{S}}-\text { solidus temperature; } \\
\Delta T-\text { solidification interval. }\end{array}$ & $T_{\mathrm{L}}-$ liquidus temperature; \\
\hline
\end{tabular}

the same and it is $\Delta T=23.3{ }^{\circ} \mathrm{C}$ for aluminum oxide and $\Delta T=11.8{ }^{\circ} \mathrm{C}$ for titanium oxide.

It can be concluded based on this that effect of nanooxides can be observed already in solidification stage, that changes its conditions to the side of quicker propagation, may be as a consequence of appearance of additional centers of nucleus formation on the inclusions, i.e. their effect as 2nd type inoculants.

This stage of investigations does not allow determining one-valued role of nanooxides in mechanism of regulation of weld metal structure formation. They also can play a role of 3rd type inoculants. In the melt they can draw heat for own heating and reduce melt temperature under certain conditions of melting, that results in growth of solidification rate. Besides, as it was determined in works of the E.O. Paton Electric Welding Institute, their effect can also be observed at the second stage of the secondary solidification effecting austenite transformation resistance.

Accumulation and analysis of experimental data in this direction allows outlining the most significant sides of NMI effect, including for nanosize range, on weld structure formation.

\section{Conclusion}

It is shown that increase from 0.5 to $4.5 \%$ of volume fraction of nanooxides introduced in the weld pool results in increase from 0.46 to 0.87 of general NMI portion in the weld metal, at that significant structural changes take place at introduction of nanooxide, volume fraction of which does not exceede $0.5 \%$. Typical in this case is increase of fraction of inclusions of small 
size range $0.07-0.50 \mu \mathrm{m}$. Inclusions in the weld metal modified by nanooxides have increased content of oxygen, aluminum and titanium, that indicates their prime composition from oxides of these elements.

Introduction of titanium nanooxide promotes for reduction of brittle constituents of ferrite and increase of content of acicular ferrite. This results in increase of mechanical properties of the weld metal, in particular impact toughness. Introduction of nanooxides reduces weld metal solidification range, that can indicate their effect as 2nd type inoculants.

1. Takamura, J., Mizoguchi, S. (1990) Roles of oxides in steels performance - Metallurgy of oxides in steels. In: Proc. of 6th Int. Iron and Steel Conf. (Tokyo, Japan, 1990), Vol. 1, 591-597.

2. Grong, O., Kolbeinsen, L., van der Eijk, C. et al. (2006) Microstructure control of steels through dispersoid metallurgy using novel grain refining alloys. ISIJ Int., 46, 824-831.

3. Lee, T.K., Kim, H.J., Kang, B.Y. et al. (2000) Effect of inclusion size on the nucleation of acicular ferrite in welds. Ibid., 40, 1260-1268.

4. Yamamoto, K., Hasegawa, T., Takamura, J. (1996) Effect of boron on intra-granular ferrite formation in Ti-oxide bearing steel. Ibid., 36, 80-86.

5. Vanovsek, W., Bernhard, C., Fiedler, M. et al. (2013) Influence of aluminium content on the characterization of microstructure and inclusions in highstrength steel welds. Welding in the World, Issue 1, $\mathbf{5 7}, 73-83$

6. Seo, J.S., Kim, H.L., Lee, C. (2013) Effect of Ti addition on weld microstructure and inclusion characteristics of bainitic GMA welds. ISIJ Int., 53(5), $880-886$.
7. Golovko, V.V., Grigorenko, G.M., Kostin, V.A. (2011) Influence of nanoinclusions on formation of weld metal structure of ferritic-bainitic steels (Review). Zbirnyk Nauk. Prats NUK, 4, 42-49.

8. Pokhodnya, I.K., Golovko, V.V., Stepanyuk, S.M. et al. (2012) Study of effect of titanium nanocarbides on formation of microstructure and properties of weld. FKhMM, 6, 68-75

9. Golovko, V.V., Stepanyuk, S.M., Ermolenko, D.Yu. (2012) Study of influence of nanoformation in metal on microstructure formation of weld and its mechanical properties. In: Transact. on Building, materials science, machine-building, Issue 64, 155-159.

10. Golovko, V.V., Pokhodnya, I.K. (2013) Effect of non-metallic inclusions on formation of structure of the weld metal in high-strength low-alloy steels. The Paton Welding J., 6, 2-10.

11. Golovko, V.V., Stepanyuk, S.N., Ermolenko, D.Yu. (2014) Technology of welding of high-strength lowalloy steels with introduction of titanium-containing inoculants. In: Nanosized systems and materials in Ukraine, 395-399. Kiev: Akademperiodika.

12. Golovko, V.V., Stepanyuk, S.M., Ermolenko, D.Yu. (2015) Effect of titanium-containing inoculants on structure and properties of weld metal of highstrength low-alloy steels. The Paton Welding J., 2, 14-18.

13. Grigorenko, G.M., Kostin, V.A., Golovko, V.V. et al. (2015) Effect of nanopowder inoculants on structure and properties of cast metal of high-strength low-alloy steels. Sovr. Elektrometallurgiya, 2, 32-41.

14. Kuznetsov, V.D., Loboda, P.I., Fomichov, S.K. et al. Method of electric arc welding with introduction of nanocomponents into weld pool. Pat. 98985 UA. Int. Cl. B 23K $9 / 16$. Fill. 15.12.14. Publ. 12.05.15.

15. Ragulya, A.V., Skorokhod, V.V. (2007) Consolidated nanostructural materials. Kyiv: Naukova Dumka.

Received 21.10.2015 